\title{
Translating Connotative Meaning in the Translation of the Holy Quran: Problems and Solutions
}

\author{
Noureldin Mohamed Abdelaal \\ Department of General Studies, Kolej Yayasan Pahang (KYP) \\ Kuantan, Pahang, Malaysia
}

\begin{abstract}
Connotative meaning is one of the most challenging aspects in translation, especially between two different cultures such as English and Arabic. The problem is more aggravated when the translation occurs from a sacred and sophisticated text such as the Holy Quran. As a result, losses in translation occur. This study, therefore, is an attempt to identify the losses in the translation of connotative meaning in the Holy Quran, propose strategies to reduce such losses, and identify the causes of such losses. For this purpose, seven examples were extracted from the Holy Quran and were qualitatively analysed. The analysis of the extracted data revealed that connotative meaning was quite challenging in translation and losses occurred. These problems in preserving the connotative meaning of the source text (ST) word or playing it down are due to two main causes: the first cause is the lack of equivalence, while the second one is the translator's failure to pick the most appropriate equivalent. Non-equivalence problems were mainly represented in lack of lexicalization, semantic complexity, culturally-bound terms, difference in expressive meaning, and difference in distinction of meaning between the source language (SL) and the target language (TL). Some strategies were suggested to reduce such loss in the translation of connotative meaning. These strategies include footnoting, transliteration, periphrastic translation, and accuracy of selecting the proper equivalent that can be achieved by triangulation procedures such as peerchecking and expert-checking.
\end{abstract}

Keywords: connotative meaning, the Holy Quran, translation loss, translation strategies

Cite as: Abdelaal, N. M. (2018). Translating Connotative Meaning in the Translation of the Holy Quran: Problems and Solutions. Arab World English Journal for Translation \& Literary Studies, 2 (1). DOI: http://dx.doi.org/10.24093/awejtls/vol2no1.5 